\title{
PENGEMBANGAN JOB SAFETY ANALYSIS UNTUK WORKSHOP PRAKTIK PLUMBING DI PENDIDIKAN VOKASIONAL KONSTRUKSI BANGUNAN UNIVERSITAS NEGERI JAKARTA
}

\author{
Amanda Lia Saraswati ${ }^{1}$, Tuti Iriani ${ }^{2}$, Santoso Sri Handoyo ${ }^{3}$ \\ 1,2,3 Universitas Negeri Jakarta \\ 1saraswatiamanda@gmail.com, 20tutiiriani@unj.ac.id ${ }^{3}$ santoso_handoyo@unj.ac.id
}

\author{
Diterima : 20 Agustus 2018 \\ Direvisi : 26 Januari 2019 \\ Diterbitkan : 12 September 2019 \\ DOI $\quad: 10.21009 /$ jpensil.v8i2.8438
}

\begin{abstract}
Abstrak
This study aims to develop Job Safety Analysis for plumbing practice workshop in Vocational Education of Building Construction as an effort to improve Health and Safety Management System. This research was conducted in Vocational Education Study Program of Building Construction of Faculty of Engineering, State University of Jakarta Building L Campus A UNJ, Jalan Rawamangun Muka, Jakarta 13220. The research time was conducted for 5 months ie in March 2018 s / d July 2018 consisting of three stages: preparation stage, implementation phase and data processing stage.

The type of research used in this study using Research \& Development methodology. The results showed that: Job Safety Analysis Development for plumbing practice workshop Vocational Education of Building Construction can already be implemented, based on validation results conducted by experts of Job Safety Analysis.
\end{abstract}

Keywords: Development, Job Safety Analysis, Plumbing.

\section{Pendahuluan}

Penerapan Sistem Manajemen Kesehatan dan Keselamatan Kerja sedang gencar diterapkan oleh Kementrian Tenaga Kerja untuk melindungi setiap tenaga kerja di Indonesia, tidak hanya di perusahaan namun di instansi pendidikan seperti Sekolah, Tempat Kursus hingga Perguruan Tinggi. Sesuai dengan Undang-undang Nomor. 1 Tahun 1970 Tentang Kesehatan dan Keselamatan Kerja, Pasal 2 menyatakan tentang Tempat Kerja ialah tiap ruangan atau lapangan, tertutup atau terbuka, bergerak atau tetap, dimana tenaga kerja bekerja, atau yang sering dimasuki kerja untuk keperluan suatu usaha dan dimana terdapat sumber bahaya. Hal tersebut diperkuat dengan pendapat dari (Silalahi \& Silalahi, 1985:15) menyatakan tentang Tempat Kerja tidak hanya tempat yang selalu terpapar bahaya namun mencakup semua tempat kegiatan usaha yang bersifat ekonomis maupun sosial seperti : (1) Bengkel tempat pelajaran praktek; (2) Tempat Rekreasi; (3) Rumah Sakit ; (4) Tempat Ibadah; (5) Pusat Hiburan; dan (6) Tempat Berbelanja.

Data dari Direktorat Bina Kesehatan Kerja dan Olahraga tahun 2016, tentang Grafik Kasus kecelakaan kerja yang terjadi pada tahun 2011 - 2016 di Indonesia memiliki kondisi yang tidak stabil, Pada tahun 2013 kondisi kecelakaan kerja di 
Indonesia meningkat sangat drastis dan 4 tahun kebelakang terjadi penurunan kondisi kecelakaan kerja yang cukup signifikan. Hal tersebut dikarekan oleh kurangnya pengetahuan dan rendahnya kesadaran akan pentingnya penerapan Kesehatan dan Keselamatan Kerja.

Manajemen Risiko merupakan bagian dari Sistem Manajemen Kesehatan dan Keselamatan Kerja. Risiko kegagalan (risk of failures) akan selalu ada pada suatu aktifitas pekerjaan yang disebabkan oleh perencanaan pekerjaan yang kurang sempurna, pelaksanaan yang kurang cermat, maupun akibat hal yang tidak disengaja. Salah satu risiko pekerjaan yang dapat terjadi adalah adanya kecelakaan kerja (work accident). Oleh karena itu, sedapat mungkin kecelakaan kerja harus dicegah, atau setidaktidaknya dikurangi dampaknya.

Salah satu cara pengaplikasian Manajemen Risiko ditempat kerja adalah penggunaan Metode Analisa Kecelakaan Kerja atau lebih dikenal dengan Job Safety Analysis. Setiap pekerjaan dianalisa mengenai metode pekerjaan yang akan dilakukan, melakukan pengecekan tentang potensi bahaya yang dapat terjadi, setelah itu melakukan pengendalian bahaya apabila terjadi bahaya/kecelakaan di lingkungan tempat kerja tersebut.

Penanganan masalah keselamatan kerja di tempat kerja harus dilakukan secara serius. Termasuk dilembaga pendidikan seperti dilingkungan Program Studi Pendidikan Vokasional Konstruksi Bangunan FT UNJ. Sebagai instansi perguruan tinggi yang akan mencetak tenaga pendidik yang kompeten dan juga professional, Program Studi Pendidikan Vokasional Konstruksi Bangunan FT UNJ tidak hanya mempelajari tentang teori tetapi juga praktik. Untuk menunjang keterampilan praktik, Program Studi Pendidikan Vokasional Konstruksi Bangunan memiliki 4 ruang bengkel/workshop dan 3 ruang laboratorium. Program Studi Pendidikan Vokasi Konstruksi Bangunan memiliki mata kuliah praktik di setiap semester, salah satunya adalah Praktik Plumbing. Praktik plumbing adalah mata kuliah yang memberikan ilmu tentang sanitasi dan juga penggunaan alat-alat plumbing, seperti pemasangan alat sanitasi, pembuatan uliran pipa galvanis dan juga pembuatan wadah plat. Alat kerja yang digunakan dalam praktik memiliki potensi bahaya yang tinggi seperti alat potong, mesin bor dan alat ulir. Menurut wawancara kepada dosen pengampu praktik plumbing yaitu Agphin Ramadhan kecelakaan kerja yang pernah terjadi didalam melakukan praktik plumbing adalah tergores plat baja dan rusaknya alatalat praktik dikarenakan pekerja tidak melaksanakan tata tertib dan bercanda disaat melakukan praktik. Terjadinya kecelakaan kerja tersebut semakin meyakinkan bahwa 97,4\% mahasiswa menginginkan adanya Job Safety Analysis dalam pelaksanaan praktik plumbing.

Pemilihan workshop praktik plumbing untuk dikembangkan Job Safety Analysis didasari oleh Keputusan Menteri Riset, Teknologi, dan Pendidikan Tinggi Nomor 257/M/KPT/2017 tentang Nama Program Studi pada Perguruan Tinggi bahwa Pendidikan Teknik Bangunan akan berganti menjadi Pendidikan Vokasional Konstruksi Bangunan yang nantinya akan berkewajiban menyediakan PPGV Konstruksi Bangunan, Gambar Arsitektur dan Teknologi Konstruksi dan Properti untuk Sekolah Menengah Kejuruan yang memiliki kompetensi keahlian Konstruksi Gedung Sanitasi dan Perawatan hal tersebut menjadikan bahwa workshop plumbing menjadi sarana pembelajaran yang menghubungkan antara Pendidikan Vokasional Konstruksi Bangunan dengan SMK Konstruksi Gedung Sanitasi dan Perawatan.

Semua orang (Dosen, Teknisi dan Mahasiswa) yang terlibat di bengkel/laboratorium harus ikut menjaga Kesehatan dan Keselamatan Kerja. Kesadaran akan adanya resiko bahaya dan menerapkan perilaku disiplin dan tertib dalam bekerja merupakan hal yang harus 
dibiasakan untuk bekerja secara selamat dan juga sehat.

Berdasarkan uraian tersebut di atas, menarik kiranya diadakan sebuah kajian yang terkait dengan upaya pengendalian kecelakan kerja berupa Job Safety Analysis untuk diterapkan di lingkungan kerja Pendidikan Vokasional Konstruksi Bangunan pada Jobsheet praktik kerja plumbing. Melalui "Pengembangan Job Safety Analysis untuk Workshop Praktik Plumbing di Pendidikan Vokasional Konstruksi Bangunan Universitas Negeri Jakarta”.

\section{Konsep Job Safety Analysis yang dikembangkan.}

Menurut (OHSAS 18001, 2007:5) Sistem Manajemen Kesehatan dan Keselamatan Kerja merupakan bagian dari Sistem Manajemen Organisasi yang digunakan untuk mengembangkan dan menerapkan kebijakan Kesehatan dan Keselamatan Kerja dan mengelola Resiko. Hal tersebut diperkuat dengan Peraturan Menteri Tenaga Kerja Nomor 5 Tahun 1996, Tentang Sistem Manajemen Kesehatan dan Keselamatan Kerja yang menyatakan bahwa:

Sistem Manajemen Kesehatan dan Keselamatan Kerja adalah bagian dari sistem manajemen secara keseluruhan yang meliputi struktur organisasi, perencanaan, tanggung jawab, pelaksanaan, prosedur, proses, dan sumber daya yang dibutuhkan bagi pengembangan penerapan, pencapaian, pengkajian dan pemeliharaan kebijakan keselamatan dan kesehatan kerja dalam rangka pengendalian risiko yang berkaitan dengan kegiatan kerja guna terciptanya tempat kerja yang aman, efisien dan produktif.

Persyaratan dalam penerapan Sistem Manajemen Kesehatan dan Keselamatan Kerja di lingkungan kerja adalah Manajemen Resiko. Menurut (Ramli, 2010:25), Risk Management adalah suatu proses atau perencanaan untuk menghindarkan terjadinya gangguan terhadap bisnis perusahaan. Sedangkan menurut (Budiono, 2003:45) didalam manajemen risiko, penilaian risiko sangat berpengaruh dalam menentukan akibat atau pemaparan potensi bahaya, sebab melalui penilaian risiko, maka kecelakaan akibat kerja dapat dicegah ataupun dihilangkan.

Menurut (Suardi, 2007:56) terdapat 3 langkah dalam melakukan Manajemen Risiko sebagai berikut :

1. Langkah pertama dalam proses manajemen risiko adalah melakukan identifikasi bahaya tempat kerja atau tempat yang berpeluan mengalami kerusakan. Cara sederhana untuk memulai menentukan bahaya dapat dilakukan dengan membagi area kerja berdasarkan kelompok.

2. Untuk memberikan makna terhadap suatu bahaya perlu dilakukan penilaian risiko sehingga seseorang mengetahui besarnya risiko yang dapat terjadi. Penilaian Risiko adalah proses untuk menentukan prioritas pengendalian terhadap tingkat risiko kecelakaan atau penyakit akibat kerja.

3. Untuk melakukakn pengendalian risiko (OHSAS 18001, 2007) memberikan pedoman mengenai pengendalian risiko dilingkungan kerja sebagai berikut : (a) Eliminasi, Eliminasi merupakan suatu pengendalian risiko yang bersifat permanen dan harus dicoba untuk diterapkan sebagai pilihan prioritas utama. Eliminasi adalah cara pengendalian risiko yang paling baik, karena risiko terjadinya kecelakaan dan sakit akibat potensi bahaya ditiadakan; (b) Subtitusi, Subtitusi merupakan penggantian material, bahan, proses yang mempunyai nilai risiko yang tinggi depan yang mempunyai nilai risiko lebih kecil; (c) Pengendalian Teknis, Pengendalian atau rekayasa teknik termasuk merubah struktur objek kerja untuk mencegah seseorang terpapar kepada potensi bahaya, seperti pengaman mesin, alat bantu mekanik; (d) Pengendalian Administratif, Pengendalian Administratif dengan mengurangi atau 
menghilangkan kandungan bahaya dengan memenuhi prosedur atau instruksi. Pengendalian tersebut diantaranya adalah mengurangi pemaparan terhadap kandungan bahaya dengan pergiliran atau perputaran kerja (job rotation), sistem ijin kerja, atau hanya dengan menggunakan tanda bahaya. Pengendalian administratif tergantung pada perilaku manusia untuk mencapai keberhasilan; dan (e) Penggunaan Alat Pelindung Diri, Alat pelindung diri dikenakan oleh pekerja sebagai pelindung terhadap bahaya. Dengan memberikan alat pengaman ini dapat mengurangi keparahan risiko yang timbul. Keberhasilan pengendalian ini tergantung dari alat pelindung diri yang dikenakan itu sendiri, artinya alat yang digunakan haruslah sesuai dan dipilih dengan benar.

Salah satu bentuk dalam mengaplikasikan manajemen resiko kerja, di tempat kerja adalah menggunakan metode Job Safety Analysis. Kegiatan tersebut dilakukan dengan melakukan penilaian resiko dan identifikasi bahaya disetiap tahapan melakukan pekerjaan/tugas yang dilakukan setiap tenaga kerja.

Menurut (OSHA 3071, 2002), Job Safety Analysis adalah Teknik yang berfokus pada tugas pekerjaan sebagai cara untuk mengidentifikasi bahaya sebelum terjadi insiden atau kecelakaan kerja. Berfokus pada hubungan antara pekerja, tugas, alat dan lingkungan kerja. Idealnya setelah dilakukan identifikasi bahaya yang tidak terkendali tentunya akan diambil tindakan dan langkah-langkah untuk menghilangkan atau mengurangi tingkat risiko yang dapat diterima pekerja.

Berdasarakan pengertian diatas maka Job Safety Analysis adalah Metode yang digunakan untuk mengidentifikasi bahaya terhadap hubungan antara pekerja, tugas, alat dan lingkungan kerja. Digunakan sebagai solusi yang dapat mengurangi dan menghilangkan bahaya di tempat kerja.

Didalam melaksanakan program Job Safety Analysis, (Ramli, 2010:152) menyatakan bahwa, terdapat 5 langkah dasar yang harus dilakukan dalam penyusunan Job Safety Analysis yaitu : (1) Menentukan pekerjaan yang akan dianalisis; (2) Menguraikan pekerjaan menjadi langkah-langkah dasar; (3) Mengidentifikasi bahaya pada masing-masing pekerjaan; (4) Mengendalikan bahaya; dan

Komunikasikan kepada semua pihak yang terlibat.

\section{Workshop Praktik Kerja Plumbing}

Menurut Undang-undang No. 1 Tahun 1970 tentang Keselamatan Kerja pasal 1 ayat 1, yang dimaksud tempat kerja adalah tiap ruangan atau lapangan, tertutup atau terbuka, bergerak atau tetap, dimana tenaga kerja bekerja, atau yang sering dimasuki tenaga kerja untuk keperluan suatu usaha dan dimana terdapat sumber atau sumbersumber bahaya.

Workshop praktik plumbing merupakan tempat kerja yang memiliki potensi bahaya. Menurut (Ismara I, Prianto E, 2017:206) Bengkel/Workshop adalah sarana dan tempat mendukung kegiatan pelatihan dan tempat peningkatan keterampilan, dalam rangka pengembangan pemahaman dan keterampilan yang sesuai dengan bidang keahlian.

Berdasarkan Peraturan Menteri Pendidikan Nasional Nomor. 40 Tahun 2008 yang berisi tentang Standar Sarana dan Prasarana Sekolah Menengah Kejuruan terdapat standar prasarana ruang praktik untuk Bengkel Plumbing dan Sanitasi.

Workshop praktik plumbing dan sanitasi berfungsi sebagai tempat berlangsungnya kegiatan pembelajaran seperti pemasangan alat saniter dan drainase, instalasi pipa dan praktik pembelajaran plat.

Luas minimum bengkel plumbing untuk menampung 16 peserta didik untuk area kerja plumbing minimal $128 \mathrm{~m}^{2}$, dan ruang penyimpanan dan instruktur $48 \mathrm{~m}^{2}$. Berikut penjabaran mengenai rasio standar 
sarana dan prasarana ruang bengkel praktik plumbing.

\section{Tujuan Penelitian}

Berdasarkan rumusan masalah, maka tujuan penelitian ini untuk mengembangkan Job Safety Analysis di Workshop Praktik Plumbing Program Studi Pendidikan Vokasional Konstruksi Bangunan Universitas Negeri Jakarta sebagai salah satu upaya untuk meningkatkan Sistem Manajemen Kesehatan dan Keselamatan Kerja.

\section{Metode Penelitian}

Penelitian ini dilaksanakan di Program Studi Pendidikan Vokasional Konstruksi Bangunan Universitas Negeri Jakarta. Bertempat di jalan RawaMangun Muka Nomor 1, Jakarta Timur. Penelitian hanya melibatkan penyelenggaraan pembelajaran Keterampilan Praktik Plumbing mahasiswa Program Studi Pendidikan Vokasional Konstruksi Bangunan yang diikuti oleh 71 mahasiswa yang ditangani oleh 2 dosen. Dilakukan pada semester Genap tahun ajaran 2017/2018 (semester 108) yaitu dibulan (Maret - Juli 2018).

Metode yang digunakan dalam penelitian ini adalah Penelitian dan Pengembangan (Research and Development) metode Borg and Gall yang disederhanakan menjadi tahapan Level 1. Disebut penelitian dan pengembangan karena merupakan kajian sistematis mengenai proses perancangan, pengembangan dan evaluasi yang bertujuan untuk menghasilkan produk yang belum pernah dikembangkan sebelumnya di Program Studi Pendidikan Vokasional Konstruksi Bangunan.

Sasaran utama dari produk yang dikembangkan adalah mahasiswa program studi Pendidikan Vokasional Konstruksi
Bangunan yang sedang mengambil mata kuliah praktik plumbing. Job Safety Analysis dikembangkan utnuk membantu program pembelajaran praktik plumbing dan meningkatkan Sistem Manajemen Kesehatan dan Keselamatan Kerja di bengkel praktik plumbin

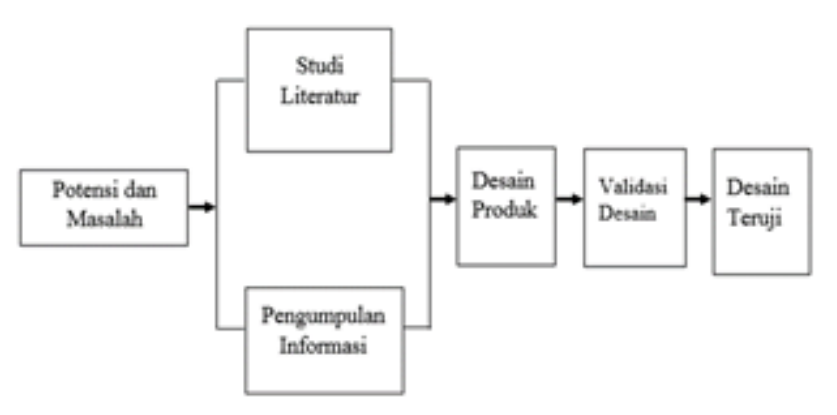

\section{Gambar 1. Metode Penelitian \& Pengembangan Borg \& Gall Level 1}

\section{Pembahasan Hasil Penelitian}

Penelitian ini memiliki 3 tahap utama yaitu analisa kebutuhan terhadap produk yang dibuat yaitu Job Safety Analysis, pengumpulan data dengan observasi workshop Praktik Plumbing dan Validasi instrument Job Safety Analysis kepada para ahli.

1. Analisa Kebutuhan, dilakukan dengan penyebaran kuisioner kepada responden yaitu mahasiswa Pendidikan Vokasional Konstruksi Bangunan Universitas Negeri Jakarta angkatan 2013 2015. Berdasarkan hasil angket yang disebar diketahui bahwa 94,9\% mahasiswa menjawab bahwa mereka mengerti tentang potensi bahaya yang dapat terjadi saat mereka melakukan praktik plumbing, namun hanya 38,5\% yang memahami cara pengendalian dari bahaya yang terjadi, dan 97,4\% menyatakan bahwa dibutuhkan adanya pengembangan Job Safety Analysis untuk workshop praktik plumbing.

2. Observasi workshop praktik plumbing, untuk melengkapi hasil penelitian dilakukan observasi dengan hasil sebagai berikut bahwa perlu adanya penataan ulang 
penempatan barang pada workshop praktik plumbing sehingga ruang kerja pekerja lebih luas, untuk ukuran ruangan sudah sesuai dengan standar yang berlaku yaitu $133 \mathrm{~m}^{2}$ untuk 16 orang pekerja. Mesin yang terdapat didalam workshop perlu mendapat perhatian dikarenakan belum adanya perlindungan mesin dan servis secara berskala. Administrasi pada workshop praktik plumbing sudah baik karena terdapat rubric peminjaman alat dan data inventaris alat hanya saja belum ada berita acara apabila terjadi kecelakaan saat melakukan aktivitas praktik.

3. Validasi produk pada para ahli, setelah dilakukan pembuatan produk langkah selanjutnya yang dilakukan adalah melakukan validasi produk kepada para ahli, dalam penelitian ini validasi diberikan kepada ahli pengembangan instrument, ahli materi, dan ahli Kesehatan dan Keselamatan Kerja. Para ahli melakukan validasi dengan melihat kesesuaian antara instrumen yang dibuat dari metode pekerjaan, potensi bahaya hingga cara pengendaliannya.

Produk yang dibuat sebanyak 6 buah disesuaikan dengan jumlah praktik yang dilakukan. Berikut hasil validasi yang dilakukan :

Tabel 4.4 Data Hasil Validasi Instrumen Job Safety Analysis

\begin{tabular}{|c|c|c|c|c|c|c|c|}
\hline No & $\begin{array}{c}\text { Instrumen } \\
\text { Job Safety } \\
\text { Analysis }\end{array}$ & $\begin{array}{c}\text { Ahli } \\
\text { Validasi } \\
1\end{array}$ & $\begin{array}{c}\text { Ahli } \\
\text { Validasi } \\
2\end{array}$ & $\begin{array}{c}\text { Ahli } \\
\text { Validasi } \\
3\end{array}$ & $\begin{array}{c}\text { Ahli } \\
\text { Validasi } \\
4\end{array}$ & $\begin{array}{c}\text { Ahli } \\
\text { Validasi } \\
5\end{array}$ & $\begin{array}{c}\text { Hasil } \\
\text { Akhir }\end{array}$ \\
\hline 1. & $\begin{array}{l}\text { Pembuatan } \\
\text { Plat baja }\end{array}$ & $94,50 \%$ & $87,91 \%$ & $79,12 \%$ & $80,21 \%$ & 91,20 & $86,58 \%$ \\
\hline 2. & $\begin{array}{l}\text { Pemasangan } \\
\text { Pipa Galvanis }\end{array}$ & $94,11 \%$ & $91,17 \%$ & $86,76 \%$ & $80,88 \%$ & $91,17 \%$ & $88,81 \%$ \\
\hline 3. & $\begin{array}{l}\text { Pemasangan } \\
\text { Kloset Duduk }\end{array}$ & $92 \%$ & $91,1 \%$ & $82,2 \%$ & $88,8 \%$ & $83,3 \%$ & $87,48 \%$ \\
\hline 4. & $\begin{array}{c}\text { Pemasangan } \\
\text { Kloset } \\
\text { Jongkok }\end{array}$ & $92,13 \%$ & $87,64 \%$ & $94,38 \%$ & $87,64 \%$ & $94,38 \%$ & $91,23 \%$ \\
\hline 5. & $\begin{array}{c}\text { Pemasangan } \\
\text { Urinoir }\end{array}$ & $92,75 \%$ & $94,20 \%$ & $85,50 \%$ & $89,85 \%$ & $76,81 \%$ & $87,82 \%$ \\
\hline 6. & $\begin{array}{c}\text { Pemasangan } \\
\text { Wastafel }\end{array}$ & $90,90 \%$ & $97,4 \%$ & $80,51 \%$ & $89,61 \%$ & $76,62 \%$ & $87,00 \%$ \\
\hline
\end{tabular}

Dari data yang didapat diketahui bahwa hasil akhir dari kesesuaian setiap pekerjaan menunjukan angka $>81 \%$ maka dapat dinyatakan bahwa Job Safety Analysis yang dibuat sudah dapat diterapkan dimasa yang mendatang.

\section{Kesimpulan}

Dari hasil pengembangan yang dilakukan, maka dapat ditarik kesimpulan bahwa Job Safety Analysis yang dikembangkan sudah dapat diimplementasikan di Workshop plumbing Universitas Negeri Jakarta, hal tersebut didasari oleh hasil validasi yang telah diberikan oleh para ahli.

Dengan adanya pengembangan Job Safety Analysis akan meningkatkan Sistem Manajemen Kesehatan dan Keselamatan Kerja di workshop plumbing, hal tersebut akan semakin baik jika ditunjang dengan kondisi workshop yang baik, perlu adanya upaya dari instansi untuk melakukan pembenahan kondisi workshop.

\section{Implikasi}

Berdasarkan kesimpulan diatas, maka implikasi yang didapat setelah penelitian ini dilakukan adalah :

1. Job Safety Analysis yang dibuat dapat meningkat Sistem Manajemen Kesehatan dan Keselamatan Kerja, dikarenakan pekerja menjadi lebih waspada dan disiplin dalam menjalankan aktivitas pekerjaan.

2. Job Safety Analysis yang dibuat dapat dijadikan sebagai salah satu alat untuk menerapkan Kesehatan dan Keselamatan Kerja di workshop plumbing Pendidikan Vokasional Konstruksi Bangunan.

3. Penelitian ini juga dapat dijadikan sarana informasi untuk workshop plumbing agar semakin meningkatkan kondisi Kesehatan dan Keselamatan Kerja di lingkungan workshop agar seluruh pekerja yang berada di lingkungan tersebut lebih merasa 
aman dan nyaman saat melakukan praktik.

\section{Saran}

Berdasarkan hasil penelitian ini maka ada beberapa saran yang peneliti dapat sampaikan, diantaranya :

1. Workshop perlu dilakukan Audit Kesehatan dan Keselamatan Kerja dari lembaga yang khusus agar memberikan rasa aman dan nyaman untuk pekerja yang ada didalamnya.

2. Perlu dilakukan uji efektivitas untuk mengetahui tingkat keberhasilan dari Job Safety Analysis yang diterapkan, sehingga mengetahui hasil jangka panjang dari instrument tersebut.

3. Penggunaan Instrumen penilaian praktik dapat dijadikan sebagai salah satu penilaian mata kuliah yang dapat diterapkan untuk meningkatkan kompetensi mahasiswa mengenai ilmu Kesehatan dan Keselamatan Kerja.

4. Penggunaan Job Safety Analysis dapat membantu mahasiwa, dosen dan laboran untuk meningkatkan Kesehatan dan Keselamatan Kerja dan melindungi pekerja dari bahaya.

\section{Daftar Pustaka}

Hargiyanto, P. (2010). Analisis kondisi dan pengunendalian bahaya di bengkel/ laboratorium sekolah menengah kejuruan, 203-210.

[OSHA] Occupational Safety and Health Administration 3071. (2002). Job Hazard Analysis. U.S Department Of Labour. 1:1-2.

[OHSAS] Occupational Health and Safety Management System 18001. (2007). Sistem Manajemen Keselamatan dan
Kesehatan Kerja - Persyaratan. Terjemahan Oleh : Jack Matatula.

Ramli, S. (2010). Pedoman Praktis Manajemen Risiko dalam Perspektif K3. Jakarta: Dian Rakyat.

Republik Indonesia. 1970. Undang-Undang Republik Indonesia No.1 Tahun 1970 tentang Kesehatan dan Keselamatan Kerja. Jakarta : Sekretariat Negara.

Republik Indonesia. 2008. Peraturan Menteri Pendidikan Nasional No.40 Tahun 2008 tentang Standar Sarana dan Prasarana Sekolah Menengah Kejuruan. Jakarta.

Silalahi, B., \& Silalahi, R. (1985). Manajemen Keselamatan dan Kesehatan Kerja. Jakarta: PT. Pustaka Binaman Presindo.

Sugiyono. (2015). Metode Penelitian dan Pengembangan (Research and Development). Bandung: Alfabeta. 
Jurnal Pendidikan Teknik Sipil 